\title{
APPLICATION OF TAGUCHI TECHNIQUE TO OPTIMIZE THE GMA WELDING PARAMETERS AND STUDY OF FRACTURE MODE CHARACTERIZATION OF AISI 304H WELDED JOINTS
}

\author{
S. A. RIZVI \\ Mechanical Engineering Department, Indian Institute of Technology (BHU), Varanasi and faculty member in U. P., J. M. I. \\ New Delhi, India \\ E-mails: sarizvi1@jmi.ac.in, saritbhu@gmail.com
}

\begin{abstract}
This research article is focusing on the optimization of different welding process parameters which affect the weldability of stainless steel (AISI) 304H, Taguchi technique was used to optimize the welding parameters and the fracture mode characterization was studied. A number of experiments have been conducted. L9 orthogonal array $(\mathrm{OA})(3 \times 3)$ was applied. Analysis of variance (ANOVA) and signal to noise ratio (SNR) was applied to determine the effect of different welding parameters such as welding current, wire feed speed and gas flow rate on mechanical, microstructure properties of SS304H. Ultimate tensile strength (UTS), toughness, microhardness (VHN), and mode of fracture was examined to determine weldability of AISI 304H and it was observed from results that welding voltage has major impact whereas gas flow rate has minor impact on ultimate tensile strength of the welded joints. Optimum process parameters were found to be 23 V, 350 IPM travel speed of wire and 15 1/min gas flow rate for tensile strength and mode of fracture was ductile fracture for tensile test specimen.
\end{abstract}

Keywords: GMAW/MIG, mechanical properties, ANOVA, stainless steel, mode of fracture, SEM, weldability

\section{Introduction}

Metal inert gas welding or gas metal arc welding process (MIG/GMAW) is an advanced version of electric arc welding in which no pressure is applied during the welding process and arc is created between a continuous copper coated wire and workpiece [1]. This GMAW is a commonly used method for joining of steel structural components for the automotive industry $[2,3]$. AISI 304 or $304 \mathrm{~L}$ is the modern evolution of the novel " $18-8$ " austenitic stainless steel. This steel is a very inexpensive and versatile anti-corrosion stainless steel, suitable for a broad range of general purpose use. AISI $304 \mathrm{H}$ has a higher chromium and lower carbon content. Lower carbon contents reduce chromium carbide precipitation during the process and its susceptibility to intergranular corrosion. AISI $304 \mathrm{H}$ is frequently used in various industries such as chemical and petrochemical, processing industries, pressure vessels, tanks, valves and pumps, heat exchangers, piping systems, flanges, fittings, medical, pharmaceutical processing, food, beverage processing and nuclear industries due to its excellent tensile strength, good weldability, and better corrosion resistance properties [4].
Dinesh Mohan Arya et al. [5] investigated process parameters for metal inert gas welding and they reported that welding current is having maximum percentage contribution to experimental work. Nabendu Ghosh et al. [6] optimized the metal inert gas welding parameters, by Grey-based Taguchi technique and they reported in their result that current has a major impact in influencing the tensile strength of welded joint as compared to the gas flow rate.

Doniavi et al. [7] optimized and predicted mechanical properties of St52 with gas metal arc welding by application of RSM and ANOVA technique and they mentioned in their result that the lower the temperature difference between the weld HAZ areas the lower the tensile stress in weld line. The Tensile strength of welded joint increases on increasing the $\mathrm{CO}_{2}$ gas percentage in shielding gas and maximum error between predicted and experimental values for tensile strength observed $0.44 \%$. Abhishek Prakash et al. [8] determined the (welding) process parameters which influence the mechanical properties by applying the Taguchi method and they produced a result that welding current has the greatest influence on tensile strength and hardness in the weldability of weld-

This is an open-access article distributed under the terms of the Creative Commons Attribution-NonCommercial 4.0 International License (https://creativecommons.org/licenses/by-nc/4.0/), which permits unrestricted use, distribution, and reproduction in any medium for non-commercial purposes, provided the original author and source are credited, a link to the CC License is provided, and changes - if any - are indicated. 
ed joint followed by wire feed speed and arc voltage. Bayazida et al. [9] predicted welding variables like travel speed, rotational speed and position of plates on mechanical and microstructural properties of friction stir welded joint of two dissimilar aluminum alloys, i.e. AA6063 and AA7075 with Taguchi technique and they reported that rotational speed, travel speed, and plates position have 59,30 , and $7 \%$ influence on tensile strength of welded joint, respectively.

Saurav Datta et al. [10] developed a multi-response problem to optimize parameters by combining to yield favorable bead geometry of submerged arc welding bead on-plate weldment and they coupled the Taguchi optimization method with Grey relation technique to evaluate the optimal parametric combination for deeper penetration, minimum bead height and depth HAZ of welded part.

Kalita and Barua [11] investigated the effect of the process parameters of metal inert gas welding such as welding current, arc voltage and shielding gas flow rate on tensile strength of welded joints by the Taguchi optimization method and they concluded that welding voltage has significant effect, both on mean and variation of the tensile strength of the weld having $87.019 \%$ and $85.398 \%$ contribution, respectively, whereas welding current has significant effect on mean only ( $10.807 \%$ contribution) whereas shielding gas flow rate has insignificant effect on the tensile strength of the welded joint.

Therefore in this research article, an attempt has to be made to optimize the process parameters of metal inert gas (MIG) welding. Chikhale et al. [13] predicted the mechanical performance of AA 6061T6 by metal inert gas welding and they consider the welding current, arc voltage and wire feed speed as welding parameters and finally they optimized the parameters by reporting that welding current has principal impact on the Tensile strength, depth of penetration and toughness of weld joint. Rizvi et al. [14] optimized different welding process parameters by application of Taguchi technique on MIG welding during bonding of IS2062 steel and they mentioned in their outcome that welding voltage and welding current have major impact on tensile strength of welded joint whereas gas flow rate has least significant effect on tensile strength of the welding. Liu et al. [16] investigate the tensile behaviour and fracture characteristics of SS clad plate by vacuum rolling and they observed that tensile ductility increases with increasing rolling temperature. Ramesh Kumar Buddu et al. [17] investigate mechanical properties, microstructure and fracture morphology of SS304L plate welded by laser welding and they find in their result that tensile fracture has revealed ductile fracture mode with fine dimples and impact fracture test having lower value for weld zone, heat affected zone
(HAZ) as compared to base metal. Hasanzadeh et al. [18] investigated the Mechanical properties of polycarbonate friction stir welded samples with different nanoalumina content. Taguchi method was employed to determine the effect of welding parameters and they demonstrated in their result that the weight percentage of nanoalumina is the most effective parameter on the tensile strength and hardness of welded nanocomposite samples.

Choudhary and Duhan [19] determined the effect of flux on properties of SS 304 using TIG welding on ultimate tensile strength, percentage elongation, Penetration depth, width and depth to width ratio and from experimental result it was found that under the same welding condition, the $\mathrm{MnO}_{2}$ and $\mathrm{Fe}_{2} \mathrm{O}_{3}$ fluxes can produce the greatest improvement in penetration capability, up to 2-3 times.

Rizvi and Tewari [20] determined the effect of different welding parameters on mechanical properties and microstructure of SS 304H welded joint with MIG welding process and it was reported that on changing the gas flow rate and wire feed speed, microstructure and mechanical properties of weldment changed. Impact tests reveal that toughness of the welded joint increases with increasing in welding current, while ultimate tensile strength (UTS) first increases and then decreases Singh et al. [21] applied Taguchi technique to determine the effect of friction stir welding (FSW) on tensile properties of AA6063 under different welding conditions and authors observed from their result that tensile strength of AA6063 welded joint increases with increasing the rotational speed and reduces with increasing transverse feed. Rizvi and Tewari [22] coupled Taguchi technique with grey relational analysis to optimize the process parameter during the welding of SS304 by MIG welding. It was observed that wire feed speed had most significant effect followed by voltage and gas flow rate. Shanti Lal Meena et al. [23] investigated the metallurgical and microhardness across the various zones of the welding in synergic MIG of SS304 and it was observed that pearlite content and the range of size distribution for the base metal and the weld zone are almost the same. While the pearlite content for the HAZ is higher and the numbers of grains is greater, the increased pearlite content combined with finer microstructure results in greater micro hardness in the HAZ. Also, it can be observed that the microhardness is greatest in the grain refined region.

\section{Design and experimental work}

\subsection{Workpiece material}

In this research article stainless steel (AISI) $304 \mathrm{H}$ was used as raw material. The AISI $304 \mathrm{H}$ plate of dimen- 


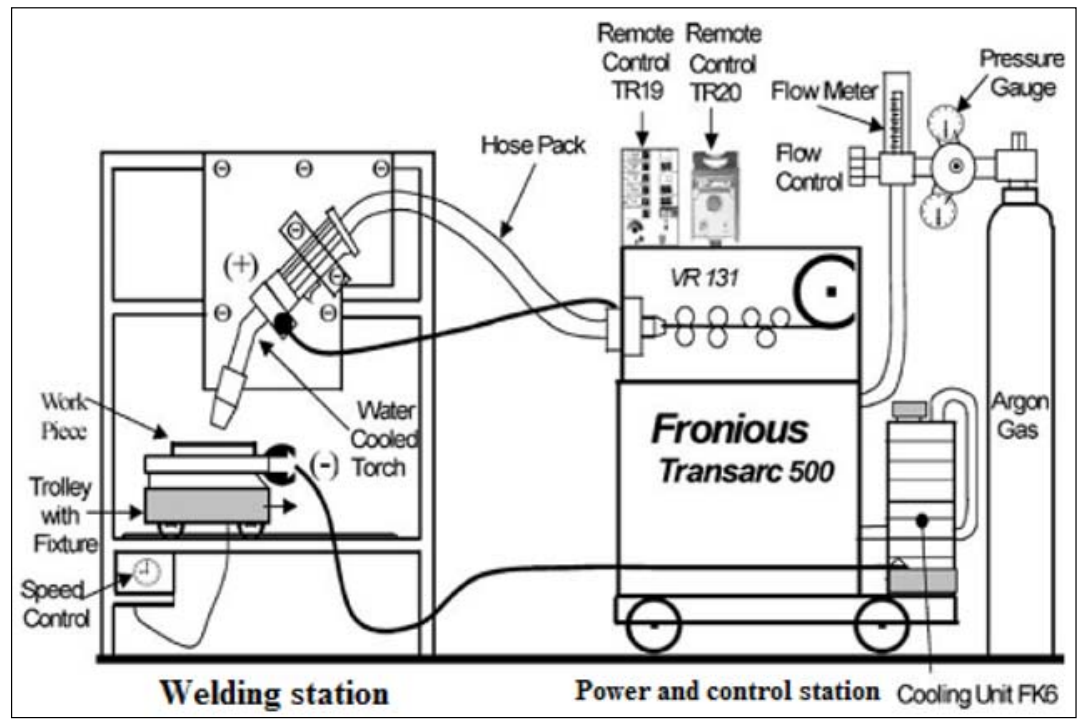

Fig. 1. Schematic diagram of GMA welding setup [15]

sion $150 \mathrm{~mm} \times 60 \mathrm{~mm} \times 5 \mathrm{~mm}$ were bonded by using gas metal arc welding (GMAW) machine with Polarity direct current electrode negative (DCEN). A schematic diagram of set of the GMAW is shown in Fig. 1.

After completed weld, welded plates were machined on the horizontal milling machine for generating V-groove. The chemical composition of parent metal plate AISI $304 \mathrm{H}$ and filler rod used in the process for welding purpose are given in Table 1, respectively.

In recent years, other intelligent algorithms technique such as artificial neural networks (ANN) [26, 27], genetic algorithm (GA) [28] and particle swarm optimization (PSO) [29] have become popular in determining and optimizing of weld quality. But for this work, Taguchi method was selected for optimization of process parameters. Taguchi design of the experiment is a simple and fool proof approach, which is used to reduce the analysis up to an optimal level. In this research article, three factors were selected with their levels as shown in Table 2, selection of the orthogonal array was based on DOF. The degree of freedom for all three factors is 6 in this design and welded by GMAW process with different welding parameters, nine tensile test specimens were cut from welded piece longitudinally; vertical milling machine is used to produce an arc of $R=12.5 \mathrm{~mm}$ and to produce "V" notch in charpy impact test specimens. Tensile test specimens are prepared as per American Society of Testing of Materials (ASTM) standard and a standard tensile test sample is shown in Fig. 2.

All tensile test specimens are tested on UTM-40 $\mathrm{T}$ at room temperature. Tensile test specimens after fracture are shown in Fig. 3. Three different welding parameters are used to perform the welding. In entire, this research work pure argon (Ar) was used as shielding gas to avoid any contamination of weld pool, as pure argon has special characteristics.

Table 1. Composition of parent metal and filler wire

\begin{tabular}{lccccccccc}
\hline Material & $\mathrm{C}(\%)$ & $\mathrm{Cr}(\%)$ & $\mathrm{Ni}(\%)$ & $\mathrm{Mn}(\%)$ & $\mathrm{Si}(\%)$ & $\mathrm{P}(\%)$ & $\mathrm{S}(\%)$ & $\mathrm{Cu}$ & $\mathrm{Fe}$ \\
\hline Base plate & 0.06 & 18.68 & 8.54 & 1.9 & 0.41 & 0.031 & 0.005 & - rest \\
Filler wire & 0.08 & $19.5-22.0$ & $9.0-11.0$ & $1.0-2.5$ & $0.3-0.65$ & 0.030 & 0.03 & 0.75 rest \\
\hline
\end{tabular}

Table 2. Input (welding) parameters with their level

\begin{tabular}{lccc}
\hline Variable & Level I & Level II & Level III \\
\hline Voltage (V) & 21 & 22 & 23 \\
Gas flow rate (1/min) & 10 & 15 & 20 \\
Wire feed rate (IPM) & 300 & 350 & 400 \\
\hline
\end{tabular}




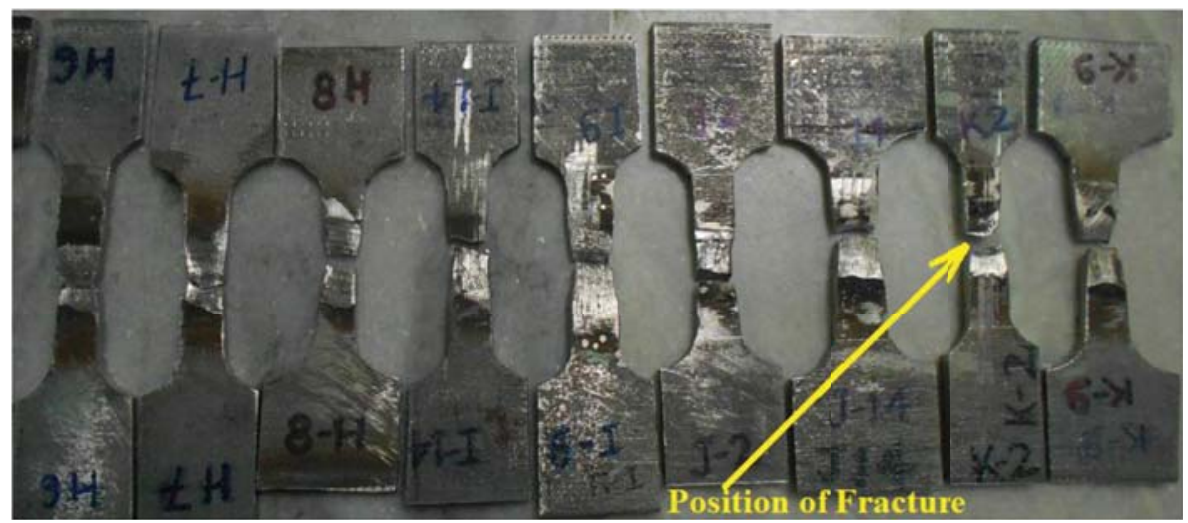

Fig. 3. Tensile test specimen after fracture

Table 3. Result for tensile strength hardness and impact toughness

\begin{tabular}{lccccccccc}
\hline $\begin{array}{l}\text { Experiment } \\
\text { No. }\end{array}$ & Voltage & $\begin{array}{c}\text { Gas flow } \\
\text { rate }\end{array}$ & $\begin{array}{c}\text { Wire feed } \\
\text { speed }\end{array}$ & UTS & SNRA1 & $\begin{array}{c}\text { Micro- } \\
\text { hardness }\end{array}$ & SNRA2 & $\begin{array}{c}\text { Impact } \\
\text { strength }\end{array}$ & SNRA3 \\
\hline 1 & 21 & 10 & 300 & 540 & 54.6479 & 171 & 44.6599 & 170 & 44.6090 \\
2 & 21 & 15 & 350 & 610 & 55.7066 & 183 & 45.2490 & 234 & 47.3843 \\
3 & 21 & 20 & 400 & 446 & 52.9867 & 200 & 46.0206 & 210 & 46.4444 \\
4 & 22 & 10 & 350 & 574 & 55.1782 & 233 & 47.3471 & 222 & 46.9271 \\
5 & 22 & 15 & 400 & 571 & 55.1327 & 210 & 46.4444 & 142 & 43.0458 \\
6 & 22 & 20 & 300 & 491 & 53.8216 & 187 & 45.4368 & 184 & 45.2964 \\
7 & 23 & 12 & 400 & 596 & 55.5049 & 205 & 46.2351 & 216 & 46.6891 \\
8 & 23 & 15 & 300 & 620 & 55.8478 & 176 & 44.9103 & 160 & 44.0824 \\
9 & 23 & 20 & 350 & 569 & 55.1022 & 216 & 46.6891 & 196 & 45.8451 \\
\hline
\end{tabular}

\subsection{Welding parameters}

In this research article, parameters which were used in welding operation are listed in Table 2.

In the present research, an L9 OA with 3 columns and 3 rows were used. This array can handle three level process parameters. Nine experiments conducted to study the welding parameters using the L9 OA. OA and the corresponding values of welding parameters are listed in Table 3.

\section{Results}

\subsection{Evaluating the signal-to-noise $(S / N)$ ratios}

Noise factors are those uncontrollable factors which affect the process result (output), whereas derived response is known as signal. The variation of index is known as $\mathrm{S} / \mathrm{N}$ ratio. Variations are usually of three types, i.e. "lower is better", "higher is better" and "normal is better". In the present experimental work UTS, microhardness, toughness (impact strength) were output (weld quality). For good quality of weld hardness, impact strength and UTS were considered as "higher is better". In order to evaluate the influence of each selected factor on the responses, $\mathrm{S} / \mathrm{N}$ ratios for each control factor were calculated.

In the present research work, tensile strength, microhardness and impact strength of welded pieces were acknowledged as the responses, hence, "higher the better" were considered for ultimate tensile strength and "nominal the best" for hardness properties for analysis purpose.

$$
\mathrm{S} / \mathrm{N}=-10 \log _{10}\left(\sum_{i=0}^{n} y_{i}^{-2}\right)
$$

Higher is better

$$
\mathrm{S} / \mathrm{N}=-10 \log _{10}\left(n^{-1} \sum_{i=0}^{n} y_{i}^{2}\right)
$$

Lower is better

$$
\mathrm{S} / \mathrm{N}=-10 \log _{10}\left(n^{-1} \sum_{i=0}^{n}\left(y_{i}-m\right)^{2}\right)
$$

Normal is better

For tensile strength response table or signal to noise ratio are shown in Table 4. 
Table 4. Response table for signal to noise ratios

\begin{tabular}{lccc}
\hline Level & Voltage & Gas flow rate & Wire feed speed \\
\hline 1 & 54.45 & 55.11 & 54.77 \\
2 & 54.71 & 55.56 & 55.33 \\
3 & 55.49 & 53.97 & 54.54 \\
\hline Delta & 1.04 & 1.59 & 0.79 \\
Rank & 2 & 1 & 3 \\
\hline
\end{tabular}

\subsubsection{Tensile strength}

Ultimate tensile strength (UTS) was calculated experimentally, Taguchi technique was applied to analy- sis with support of ANOVA and mode of fracture was studied. On the basis of data analyzed, plots for S/N ratio are shown in Fig. 4. It is very clear from Fig. 4 that third level of voltage $(23 \mathrm{~V})$, the second level of gas flow rate $(15 \mathrm{l} / \mathrm{min})$ and second level of wire feed speed (350 IPM) produce higher tensile strength.

\subsubsection{Hardness}

Vicker hardness (VHN) of test samples were also experimentally calculated, Taguchi method was employed to find out the optimal welding process parameters with support of ANONA. On the basis of data summarized, plots for $\mathrm{S} / \mathrm{N}$ ratio are expressed in Fig. 5. From Fig. 5 it is observed that voltage (22 V),

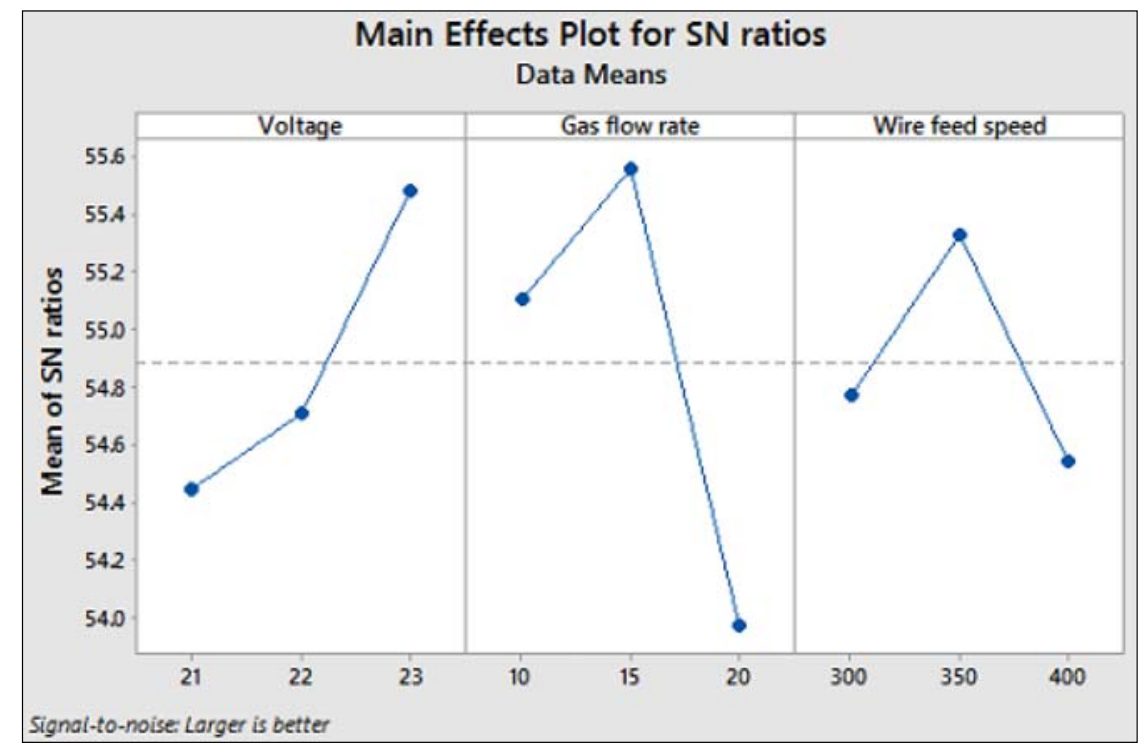

Fig. 4. Main effects plot for $\mathrm{S} / \mathrm{N}$ ratios (UTS)

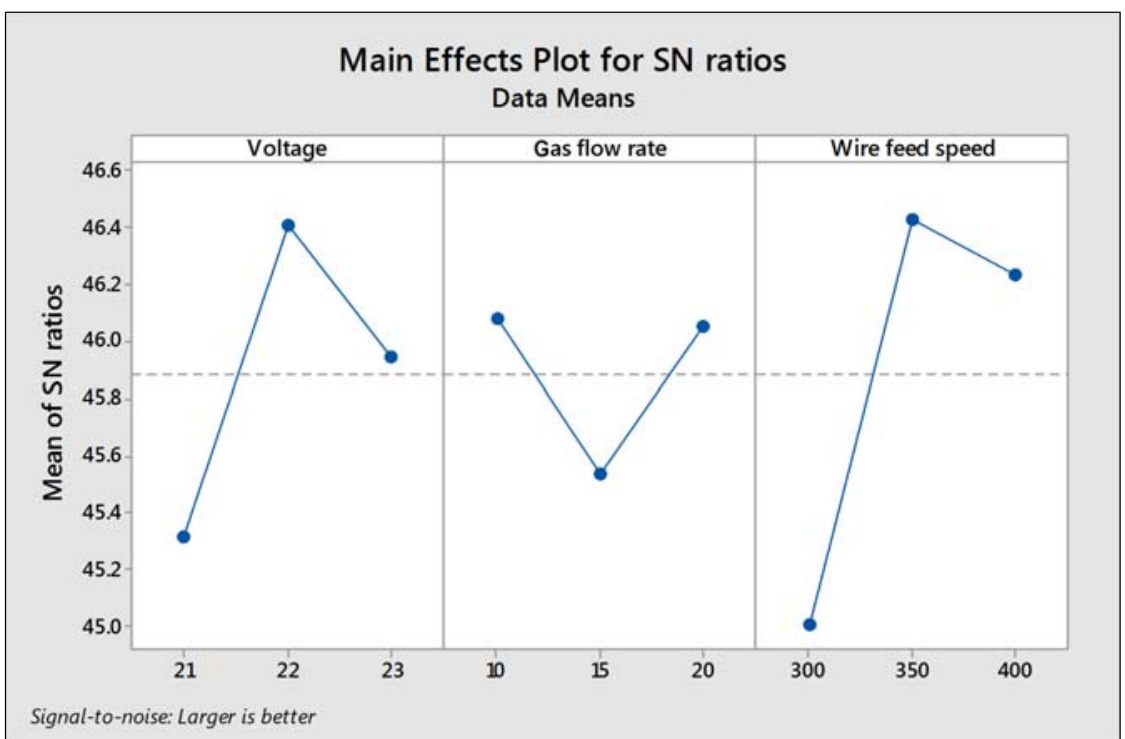

Fig. 5. Main effects plot for $\mathrm{S} / \mathrm{N}$ ratios (VHN) 
Table 5. Analysis of variance for SNRA1 (UTS) using adjusted SS for tests

\begin{tabular}{lcrrrrr}
\hline Source & DF & Adj. SS & Adj. MS & F & \multicolumn{1}{c}{ P } & Contribution (\%) \\
\hline Arc voltage & 2 & 6613.6 & 3306.8 & 11.58 & 0.079 & 25.5 \\
Gas flow rate & 2 & 15213.6 & 7606.8 & 26.65 & 0.036 & 58.7 \\
Wire feed speed & 2 & 3494.2 & 1747.1 & 6.12 & 0.140 & 13.5 \\
Error & 1 & 570.9 & 285.4 & & & 2.2 \\
\hline Total & 8 & 25892.2 & & & & \\
\hline
\end{tabular}

Table 6. Analysis of variance for SNRA2 (hardness) using adjusted SS for tests

\begin{tabular}{llrrrrr}
\hline $\begin{array}{l}\text { Source/ } \\
\text { parameters }\end{array}$ & DF & Adj. SS & Adj. MS & F & P & Contribution (\%) \\
\hline Arc voltage & 2 & 968.2 & 484.11 & 4.88 & 0.170 & 25 \\
Gas Flow rate & 3 & 310.2 & 155.11 & 1.57 & 0.390 & 58 \\
Wire feed speed & 2 & 1828.2 & 914.11 & 9.22 & 0.0985 & 14 \\
Error & 1 & 198.2 & 99.11 & & & 3 \\
\hline Total & 8 & 3304.9 & & & & \\
\hline
\end{tabular}

first level of gas flow rate $(10 \mathrm{l} / \mathrm{min})$ and second level of wire feed speed (350 IPM) give normal values of hardness.

\subsection{ANOVA}

Analysis of variance (ANOVA) is a statistic tool or technique, which is applied to evaluate the differences between the mean and their associated procedure. ANOVA results for UTS given in Table 5 show that gas flow rate has the major principal effect with $59 \%$ contribution followed by arc voltage with $25 \%$ contribution, while wire feed speed has the least effect.

ANOVA for $\mathrm{S} / \mathrm{N}$ ratio for hardness is summarized in Table 6 and it is very clear from the table that gas flow rate has the major significant impact with 58\% contribution followed by arc voltage with $25 \%$ contribution, while wire feed speed has the least effect.

\section{Mode of fracture}

\subsection{Fracture mode of the tensile test specimen}

Fracture mode of tensile test specimens was studied by SEM apparatus at room temperature. The fracture surface of AISI $304 \mathrm{H}$ welded joint obtained with MIG welding are shown in Fig. 6. Mode of fracture of the tensile test specimens was tried to be understood by the given figure. Figure $6 \mathrm{~b}$ shows the fractographs of tensile fractured surface. It is very clear from figure that mode of fracture was ductile with numerous dimples. It is also observed from the result that format of fracture is not uniform; cleavage fracture is a tear type fracture. Cleavage and secondary cleavage are clearly visible in SEM image of fracture surface and in another study it was found that impact toughness was reversely correlated with the square root of dimple size [25].

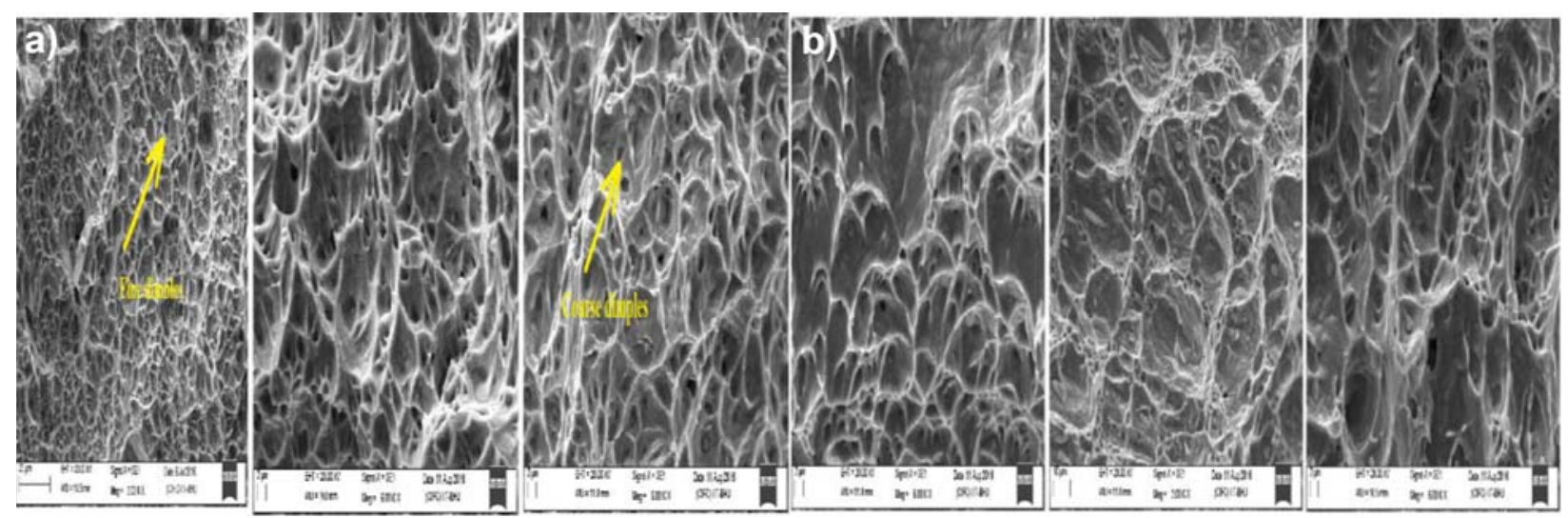

Fig. 6. Fractograph morphology (SEM) of tensile test specimens 


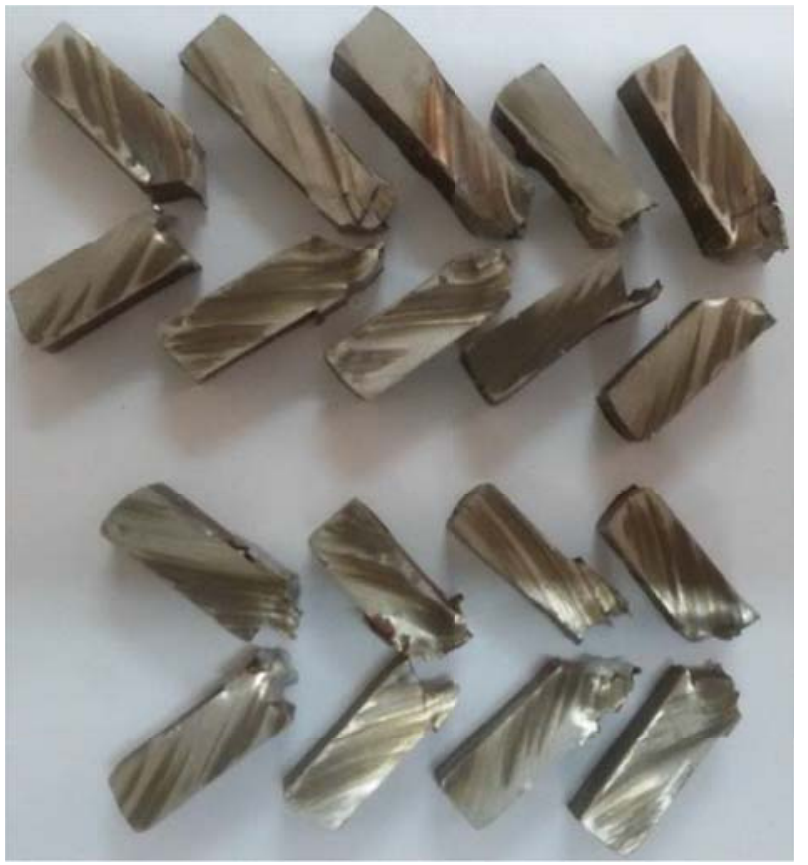

Fig. 7. Impact test samples after fracture

\subsection{Fracture mode of toughness test specimen}

To determine the toughness "V" notch charpy samples were prepared as per ASTM. Specimens after fracture are shown in Fig. 7. Impact fractured specimens were examined to determine the surface morphology.

Figure 8 shows the images of fractograph of impact charpy "V" notch test piece. Sample 1 in Fig. 8 interface between ferrite and martensite, while ductile fracture at the interface between ferrite and austenite [24] sample 2 showed shallow dimples.

\section{Conclusions}

In the present research work, the effect of gas metal arc welding (GMAW) processes on various welding variables and fracture mode characterization was studied. The welding process parameters in this experiment were: arc voltage, wire feed speed, and gas flow rate. It was found that:

- The process parameters for MIG welding of stainless steel (SS) with the optimal weldability have been marked.

- The modified Taguchi technique was applied to determine the optimal weldability with three higher-the-better quality characteristics

- The analysis showed that gas flow rate having the significant parameter that affects the UTS and $\mathrm{VHN}$ is followed by arc voltage and wire feed speed

- Ductile fracture mode was observed with fine dimples for tensile test samples,

- SEM analysis of fractured test pieces, fracture morphology showed rough dimples with the combination of ductile and brittle fracture in impact toughness welding samples

- All charpy "V" notch test samples broke from the centre line.
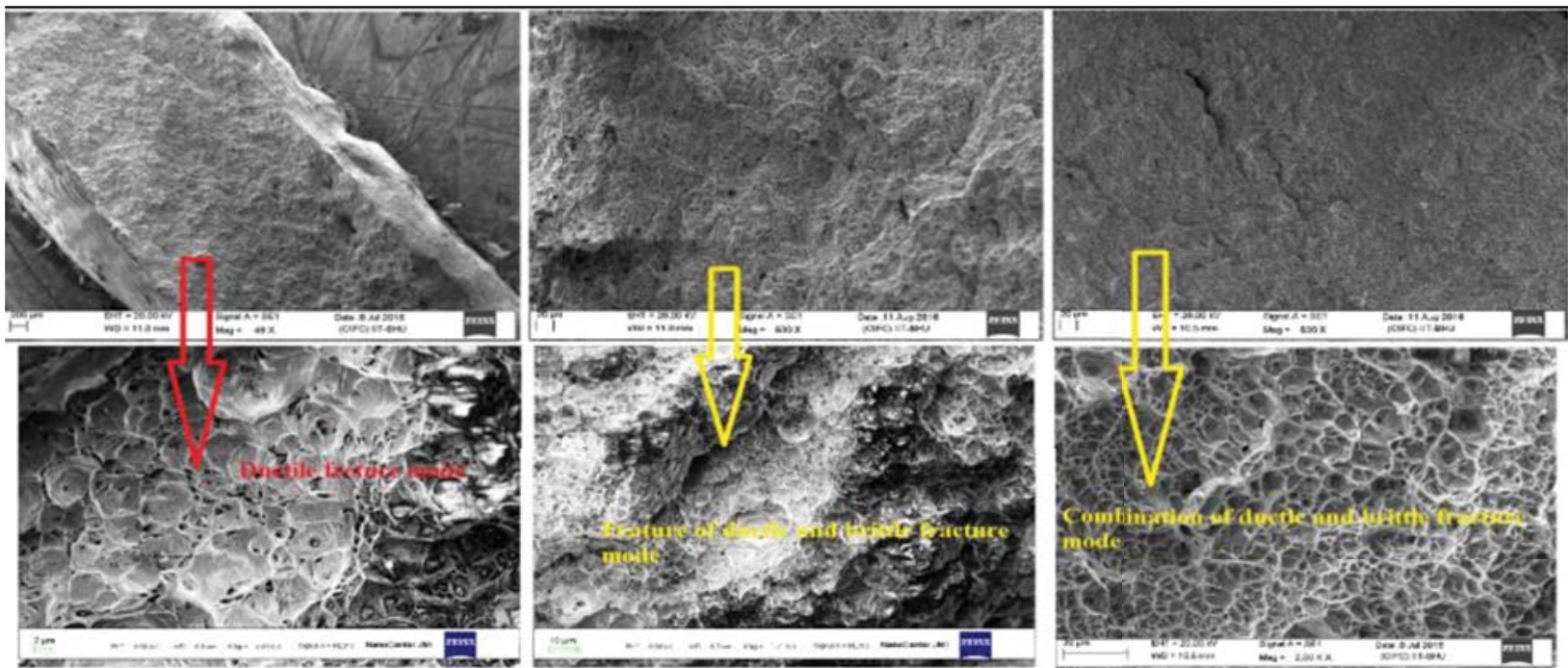

Fig. 8. Macro images and SEM images of impact fracture samples for morphology

shows the ductile fracture with coarse dimples. Enough finer dimples are observed in sample 3 in Fig. 8. Combined ductile and brittle fracture mode formation is responsible for poorly absorbed energy. Cracks initiated at soft ferrite and then triggered brittle fracture at the

\section{References}

[1] Rizvi S. A., Tewari S. P., Wajahat A. (2009), Advanced Welding Technology. Kataria \& Sons (P) Ltd., New Delhi, p. 45 
[2] Ghazvinlo H. R., Honarbakhsh A., Shadfar N. (2010), Effect of arc voltage, welding current and welding speed on fatigue life, impact energy and bead penetration of AA6061 joints produced by robotic MIG welding. Indian Journal of Science and Technology, 3(2).

[3] Ramazani A., Mukherjee K., Abdurakhmanov A., Prahl U., Schleser M., Reisgen U., Bleck W. (2014), Micromacro-characterization and modeling of mechanical properties of gas metal arc welded (GMAW) DP600 steel. Material Science \& Engineering A, 589, 1-14.

[4] Folkhard E. (1988), Welding Metallurgy of Stainless Steels. Springer-Verlag, New York.

[5] Dinesh Mohan Arya, Vedansh Chaturvedi, Jyoti Vimal (2016), Parametric optimization of MIG process parameters using Taguchi and Grey Taguchi analysis. International Journal of Research in Engineering and Applied Sciences, 3(6), 1-17.

[6] Nabendu Ghosh, Pradip Kumar Pal, Goutam Nandi (2016), Parametric optimization of MIG welding on 316L austenitic stainless steel by Grey-based Taguchi method. Procedia Technology, 25, 1038-1048.

[7] Doniavi A., Hosseini A., Ranjbary G. (2016), Prediction and optimization of mechanical properties of St52 in gas metal arc weld using response surface methodology and ANOVA, International Journal of Engineering Transactions C: Aspects, 29(9), 1307-1313.

[8] Abhishek Prakash, Raj Kumar Bag, Papin Ohdar, Siva Sankar Raju (2016), Parametric optimization of metal inert gas welding by using Taguchi approach. IJRET, 5(2), 176-181.

[9] Bayazida S. M., Farhangia H., Ghahramani A. (2015), Investigation of friction stir welding parameters of 6063 7075 aluminum alloys by Taguchi method. Procedia Materials Science, 11, 6-11.

[10] Saurav Datta, Asish Bandyopadhyay, Pradip Kumar Pal (2008), Grey-based Taguchi method for optimization of bead geometry in submerged arc bead-on-plate welding. Int. J. Adv. Manuf. Technol., 39, 1136-1143.

[11] Diganta Kalita, Barua P. B. (2015), Taguchi optimization of MIG welding parameters affecting tensile strength of C20 welds, IJETT, 26, 43-49.

[12] ASTM E8/E8M (2013), 11. Standard Test Methods for Tension Testing of Metallic Materials. ASM International

[13] Sagar R., Chikhale, Kishor P. Kolhe, Pawan Kumar (2016), Prediction of mechanical properties of Al alloy 6061-T6 by using GMAW. International Journal of Current Engineering and Technology, 5, 300-306.

[14] Rizvi S. A., Tewari S. P., Wajahat Ali (2016), Application of Taguchi technique to optimize the process parameters of MIG wedging on IS2062 steel. International Journal on Emerging Trends in Mechanical \& Production Engineering, 2(2) 1-11.

[15] Ganjigatti J. P., Pratihar D. K., Roy Choudhury A. (2008), Modeling of the MIG welding process using statistical approaches. Int. J. Adv. Manuf. Technology, 35, 1166-1190.

[16] Liu B. X., Yin F. X., Dai X. L., He J. N., Fang W., Chena C. X., Dong Y. C. (2017), The tensile behaviors and fracture characteristics of stainless steel clad plates with different interfacial status. Materials Science \& Engineering A, 679, 172-182.
[17] Ramesh Kumar Buddu, Chauhan N., Raole P. M., Harshad Natu (2015), Studies on mechanical properties, microstructure and fracture morphology details of laser beam welded thick SS304L plates for fusion reactor applications. Fusion Engineering and Design 95, 34-43.

[18] Hasanzadeh R., Azdast T., Doniavi A., Babazadeh S., Lee R. E., Daryadel M., Shishavan S. M. (2017), Welding properties of polymeric nanocomposite parts containing alumina nanoparticles in friction stir welding process. International Journal of Engineering Transactions A: Basics, 30(1), 143-151.

[19] Choudhary S., Duhan R. (2015), Effect of activated flux on properties of SS 304 using TIG welding. International Journal of Engineering Transactions B: Applications, 28(2), 290-295.

[20] Saadat Ali Rizvi, Tewari S. P. (2017), Effect of different welding parameters on the mechanical and microstructural properties of stainless steel $304 \mathrm{H}$ welded joints. International Journal of Engineering Transactions A: Basics, 30(10), 1510-1516.

[21] Singh R., Saadat Ali Rizvi, Tewari S. P. (2017), Effect of friction stir welding on the tensile properties of AA6063 under different conditions. International Journal of Engineering Transactions A: Basics, 30(4), 597-603.

[22] Saadat Ali Rizvi, S. P. Tewari (2018), Optimization of gas metal arc welding parameters of SS304 austenatic steel by Taguchi-Grey relational analysis. Journal of Computational and Applied Research in Mechanical Engineering, accepted for publishing in 10(11).

[23] Shanti Lal Meena, Ravi Butola, Qasim Murtaza, Hardik Jayantilal, Niranjan M. S. (2017), Metallurgical investigations of microstructure and microhardness across the various zones in synergic MIG welding of stainless steel. Materials Today: Proceedings, 4, 8240-8249.

[24] Rong Chen, Ping Jiang, Xinyu Shao, Gaoyang Mi, Chunming Wang, Shaoning Geng, Song Gao, Longchao Cao (2017), Improvement of low-temperature impact toughness for 304 weld joint produced by laser-MIG hybrid welding under magnetic field. Journal of Materials Processing Tech., 247, 306-314.

[25] Hilders O. A., Santana M. G. (1988), Toughness and fractography of austenitic type 304 stainless steel with sensitization treatments at $973 \mathrm{~K}$. Metallography, 21, 151-164.

[26] Singh A., Cooper D. E., Blundell N. J., Pratihar D. K., Gibbons G. J. (2014), Modelling of weld-bead geometry and hardness profile in laser welding of plain carbon steel using neural networks and genetic algorithms. Int. J. Comput. Integr. Manuf., 27(7), 656-674.

[27] Sathiya P., Panneerselvam K., Soundararajan R. (2012), Optimal design for laser beam butt welding process parameter using artificial neural networks and genetic algorithm for super austenitic stainless steel. Opt. Laser Technol., 44(6), 1905-1914.

[28] Katherasan D., Elias J. V., Sathiya P., Haq A. N. (2014), Simulation and parameter optimization of flux cored arc welding using artificial neural network and particle swarm optimization algorithm. J. Intell. Manuf., 25(1), 67-76.

[29] Chaki S., Shanmugarajan B., Ghosal S., Padmanabham G. (2015), Application of integrated soft computing techniques for optimisation of hybrid $\mathrm{CO}_{2}$ laser-MIG welding process. Appl. Soft Comput., 30, 365-374. 